\title{
BIMBINGAN BELAJAR MEMBACA AL-QUR'AN GRATIS PADA ANAK ASUH RUMAH PINTAR ACIBUDESA PURWODADI KECAMATAN PADANGSIDIMPUAN BATUNADUA
}

\author{
Samsidar, Muksana Pasaribu, Rosmaimuna Siregar, Rini Agustini, Jumaita \\ Nopriani Lubis
}

Fakultas Agama Islam Universitas Muhammadiyah Tapanuli Selatan samsidar@um-tapsel.ac.id

\begin{abstract}
In Islam, the Koran and Al-Hadith are two sources that serve as the basis for Muslims. In order to better understand and study the contents of the Al-Qur'an, a Muslim must have the ability to read the Al-Qur'an. For Muslims studying the Koran is obligatory because it contains Islamic teachings regarding the commandments and all the prohibitions so that humans are safe in the world and the hereafter. The Purwodadi area of Padangsidimpuan Batunadua district has a smart house called the Acibu (I Love Books). This smart house has foster children aged 9-12 years old belonging to elementary school children from a similar family in Purwodadi Village. The Acibu Smart House does not have programs related to the religious field, therefore it is necessary to provide children with the ability to read the Qur'an. Referring to this existing reality, it is very necessary to provide actions that enable participants to read the Qur'an by making free tutoring at the Acibu Purwodadi Smart House, Padangsidimpuan Batunadua District. This PKM activity is carried out only 2 times a week every Wednesday and Thursday with a limited time of only 3 hours a day, from 14.00 to 17.00 .
\end{abstract}

Keywords: Tutoring, Reading Al-Quran, Free

\begin{abstract}
Abstrak
Al-Qur'an dan Al-Hadist adalah dua sumber yang dijadikan sebagai landasan umat Islam dalam kehidupannya. Bagi umat Islam mempelajari Al-Qur'an hukumnya wajib, maka seorang muslim harus memiliki kemampuan membaca Al-Qur'an agar lebih bisa memahami dan mempelajari isi kandungannya. Al-Qur'an berisi ajaran-ajaran Islam tentang perintah-perintah dan segala apa laranganya supaya manusia selamat di dunia dan akherat. Wilayah Purwodadi Kecamatan Padangsidimpuan Batunadua memiliki rumah pintar yang disebut dengan Acibu (Aku Cinta Buku). Rumah pintar ini memiliki anak asuh usia 9 - 12 tahun tergolong usia anak SD berasal dari keluarga sekitas Desa Purwodadi. Rumah Pintar Acibu tidak memiliki program yang berkaitan dengan bidang keagamaan, oleh karena itu perlu rasanya untuk memberi bekal kepada anak-anak kemampuan membaca Al-Qur'an. Mengacu pada realita yang ada ini, maka sangat perlu untuk memberikan tindakan yang membuat peserta dapat membaca Al Qur'an dengan membuat bimbingan belajar gratis bertempat di rumah Pintar Acibu Purwodadi Kecamatan Padangsidimpuan Batunadua.Kegiatan PKM ini dilakukan hanya 2 kali seminggu setiap hari Rabu dan Kamis dengan waktu yang terbatas hanya 3 jam sehari yaitu dari jam 14.00 s/d 17.00 .

Kata kunci: Bimbingan Belajar, Membaca Al-Qur'an, Gratis
\end{abstract}

\section{PENDAHULUAN}

Al-Qur'an dan Al-Hadist merupakan dua sumber yang dijadikan sebagai landasan hidup umat Islam dalam menjalankan kehidupannya. Agar bisa memahami dan mempelajari isi kandungan Al-Qur'an maka seorang muslim dituntut harus memiliki kemampuan membaca Al-Qur'an supaya lebih mudah memahami isi kandungannya.

Al-Qur'anul Karim adalah firman Allah yang tidak mengandung 
kebatilan sedikitpun. Al-Qur'an member petunjuk jalan yang lurus dan member bimbingan kepada umat manusia di dalam menempuh perjalanan hidupnya, ${ }^{1}$ membacanya juga menjadi ibadah yang akan mendapatkan pahala. Bahkan membaca satu hurufnya kita dijanjikan akan mendapatkan sepuluh kebaikan. $^{2}$

Untuk dapat membaca Al-Qur'an dengan baik dan benar maka ditempuh melalui proses pelatihan. Karena pelatihan merupakan salah satu metode yang sangat penting untuk memahirkan dalam bacaan. Melalui proses pelatihan seseorang diarahkan dan dibimbing untuk dapat membaca Al-Qur'an dengan sebaik-baiknya.

Oleh karena itu, wajib bagi seluruh umat Islam untuk senantiasa menjunjung tinggi Al-Qur'an di dalam hatinya terlebih dahulu, selanjutnya di dalam kehidupan nyata yang mereka jalani baik, baik dengan membacanya, menghapalnya, mempelajarinya, mengajarkannya, berhukum dengannya, atau dalam menetapkan hukum. ${ }^{3}$

Membaca dan memahami AlQur'an merupakan keharusan bagi umat Islam, karena Al-Qur'an adalah sumber utama bagi umat Islam dalam menjalankan kehidupan sehari-harinya, sedangkan ketika berbicara tentang kemampuan membaca dan memahami Al-Qur'an selalu beragam dan bervariasi, kadang ada orang yang begitu bagus dalam pembacaan AlQur'annya akan tetapi tidak pandai memahami isi kandungannya, terkadang ada juga orang yang mampu

${ }^{1}$ Endi Suhendi Zen, Panduan Baca Tulis AlQur'an, (Jakarta Timur: CV. Indradjaya, 2013), hal. Xi.

${ }^{2}$ Abdul Lathif, Belajar Tajwid untuk Pemula, (Yogyakarta: Barokah Books, 2018), hal. 3.

${ }^{3}$ Ahmad Baduwailan, Menjadi Hafizh Tips \& Motivasi Menghafal Al-Qur'an, (Solo: Aqwam, 2017), hal. 13. membacanya dengan baik dan pandai memahami isi kandungannya, ada juga orang yang kurang begitu bagus dalam pembacaan Al-Qur'annya akan tatapi ia mampu memahami isi kandungannya, ada juga orang yang tidak pandai baca Al-Qur'an dan tidak pandai memahaminya, yang terakhir adalah orang yang seimbang, dalam artian ia mampu membaca dan memahami AlQur'an dengan baik dan benar.

Saat ini, wilayah Desa Purwodadi menurut hasil observasi menggambarkan bahwa banyak anakanak usia 9 - 12 tahun tergolong usia anak SD yang masih perlu mendapatkan bimbingan guru mengaji setelah pulang sekolah SD.Rumah Pintar Acibu di Desa Purwodadi ini belum memiliki program yang berkaitan dengan bidang keagamaan, oleh karena itu perlu rasanya untuk memberi bekal kepada anak-anak berupa kemampuan membaca Al-Qur'an sehingga mereka dapat membaca Al-Qur'an dengan baik dan benar. Mempelajari Al-Qur'an hukumnya wajib karena berisi perintahperintah dan ajaran-ajaran Islam tentang segala larangannya supaya manusia selamat di dunia dan akhirat. Dari apa yang telah diuraikan perlu disadari umat Islam bahwa upaya untuk pembelajaran Al-Qur'an sangatlah penting.

\section{Permasalahan Mitra}

Anak lebih banyak bergaul dengan masyarakat, sehingga dapat mempengaruhi sifat, watak dan perilakunya sehari-hari, oleh karena itu pendidikan dalam masyarakat sanga penting. Karena pentingnya pengetahuan tentang Al Qur'an, maka penulis berusaha mengangkat masalah ini menjadi obyek pembahasan kegiatan dengan usaha penambahan pelajaran $\mathrm{Al}$ Qur'an di luar sekolah.

Rumah Pintar Acibu Desa Purwodadi merupakan tempat belajar anak-anak di lingkungan Desa 
Purwodadi setelah pulang SD. Rumah Pintar Acibu ini belum memiliki program belajar mengaji karena kurangnya ilmu tentang penggunaan strategi untuk mengajari peserta didik untuk belajar al-Qur'an dengan baik dan benar.

\section{Solusi yang ditawarkan}

Rendahnya ekonomi keluarga menyebabkan anak-anak usia $9-12$ tahun tergolong usia anak SD yang semestinya masih perlu mendapatkan bimbingan guru mengaji setelah pulang sekolah SD, justru tidak ada yang membimbingnya, sehingga mereka tidak mendapatkan kesempatan untuk belajar al-Qur'an.

Rumah Pintar Acibu Desa Purwodadi merupakan tempat belajar anak yang dianggap cocok untuk tempat dilaksanakannya kegiatan belajar AlQur'an karena mudah dijangkau oleh peserta didik dan tidak menggunakan dana transportasi. Karena lokasi ini dilingkungan mereka beraktifitas, dengan mudah mereka dapat mengikutinya, sehingga kegiatan ini tidak banyak mengganggu aktifitasnya.

\section{Target dan Luaran}

\section{a. Target dan sasaran}

Dilaksanakannya kegiatan belajar Al-Qur'an karena mudah dijangkau oleh peserta dan tidak menggunakan dana transportasi.Setelah melewati semua tahapan kegiatan ini, peserta akan dimotivasi untuk membaca Al-Qur'an lebih bersemangat dan senang, sehingga diamalkannya dalam kehidupan sehari-hari. Dan disamping itu beban ekonomi orang tua terbantu karena kegiatan ini dilaksanakan gratis, dan tugas guru dan tokoh masyarakat juga terbantu. Ada harapan selesai kegiatan ini peserta dapat membaca ayat Al Qur'an dengan baik dan benar.
Adapu indikator keberhasilan kegiatan ini adalah:

Tabel: 1: Indikator Keberhasilan

\begin{tabular}{|c|c|c|}
\hline Indikator & Keberhasilan & Ket \\
\hline Baca & 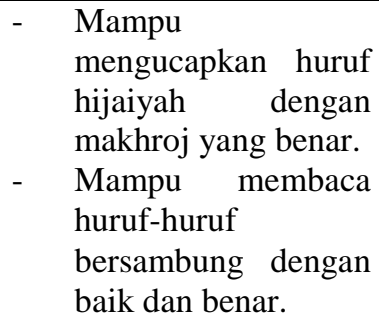 & \\
\hline Tajwid & $\begin{array}{l}\text { Mampu membaca Al- } \\
\text { Qur'an dengan panjang- } \\
\text { pendek sesuai dengan } \\
\text { tajwid yang benar. }\end{array}$ & \\
\hline
\end{tabular}

\section{b. Luaran}

Luaran yang dihasilkan dari kegiatan ini adalah:Jurnal Martabe UM-Tapsel.

\section{METODE}

\section{Rencana Kegiatan}

Dalam kegiatan ini peserta harus ditest bacaannya terlebih dahulu. Adapun materi diberikan secara bertahap dan berkesinambungan (saling terkait satu sama yang lainya). Bentuk pembelajaran Al-Qur'an yang diselenggarakan adalah dengan menggunakan metode Iqra'.Setiap kenaikan tingkat, murid diwajibkan untuk melakukan ujian terlebih dahulu. Yang bacaannya benar dan lancar bisa melanjutkan lagi ketingkat berikutnya sedang yang belum lancar harus mengikuti jilid sebelumnya hingga siap untuk mengikuti ujian lagi sampai ia bisa membaca Al-Qur'an dengan tajwid yang benar.

Programini direncanakan akan dilaksanakan selama 4 bulan, dalam waktu 2 kali seminggu.

\section{Jadwal Kegiatan}

Tabel 2. Jadwal Kegiatan

\begin{tabular}{|l|l|l|}
\hline No & Kegiatan & $\begin{array}{l}\text { Tanggal } \\
\text { dilaksanakan }\end{array}$ \\
\hline 1 & $\begin{array}{l}\text { Pembagian tugas } \\
\text { kerja }\end{array}$ & 1 September 2020 \\
\hline
\end{tabular}




\begin{tabular}{|c|c|c|}
\hline 2 & $\begin{array}{l}\text { Pembukaan } \\
\text { Kegiatan }\end{array}$ & 2 September 2020 \\
\hline 3 & $\begin{array}{l}\text { Temu mitra dengan } \\
\text { tim pelaksana } \\
\text { (untuk memantakan } \\
\text { kegiatan) }\end{array}$ & 2 September 2020 \\
\hline 4 & $\begin{array}{l}\text { Pengelompokan } \\
\text { Peserta didik }\end{array}$ & 2 September 2020 \\
\hline 5 & $\begin{array}{l}\text { Pengumpulan bahan } \\
\text { dan peralatan } \\
\text { kegiatan }\end{array}$ & $\begin{array}{ll}3-8 & \text { September } \\
2020 & \end{array}$ \\
\hline 6 & $\begin{array}{l}\text { Penyerahan Bahan } \\
\text { Pembelajaran }\end{array}$ & 9 September 2020 \\
\hline 7 & $\begin{array}{l}\text { Pembelajaran ke } 1 \\
-8\end{array}$ & $\begin{array}{l}9 \text { September }-8 \\
\text { Oktober } 2020\end{array}$ \\
\hline 8 & Evaluasi Kegiatan & $\begin{array}{l}14-15 \text { Oktober } \\
2020\end{array}$ \\
\hline 9 & $\begin{array}{l}\text { Penyusunan } \\
\text { Laporan }\end{array}$ & $\begin{array}{l}19 \text { Oktober - } 5 \\
\text { Desember } 2020\end{array}$ \\
\hline 10 & $\begin{array}{l}\text { Penggandaan } \\
\text { Laporan }\end{array}$ & $\begin{array}{ll}19-31 & \text { Desember } \\
2020 & \end{array}$ \\
\hline 11 & Publikasi & 10 Januari 2021 \\
\hline
\end{tabular}

\section{Tindak Lanjut}

Setelah melewati semua tahapan, harapannya tetap menjalin kerja sama antara pelaksana dengan mitra. Selain itu, para peserta didik diharapkan dapat membaca Al-Qur'an dengan baik dan benar.

\section{Kualifikasi Tim Pelaksana}

Tim pelaksana terdiri dari 5 orang, yaitu: ketua tim pengusul dan anggota terdiri dari 4 orang. Ketua akan langsung mengontrol jalannya semua proses kegiatan.

Dalam kegiatan ini ketua dan anggota akan mudah dalam bekerjasama karena kualifikasi ilmu yang dimiliki sama dan linear. Anggota berperan sebagai penanggungjawab kegiatan yang akan diimplementasikan pada program pengabdian kepada masyarakat. Dengan demikian, tim ini akan saling berkolaborasi dan saling melengakapi demi suksesnya kegiatan sesuai yang di harapkan. Dalam kegiatan ini tim akan memberikan pelatihan tentang bimbingan belajar membaca Al-Qur'an gratis pada anak asuh Rumah Pintar Acibu Desa Purwodadi.

\section{HASIL DAN PEMBAHASAN}

Kemampuan peserta didik membaca dan memahami tajwid AlQur'an selalu beragam dan bervariasi, ada yang mampu membaca dengan baik, ada yang tidak mampu membaca sama sekali, ada juga orang yang begitu bagus irama dalam pembacaan AlQur'annya akan tetapi tidak mampu memahami tajwidnya, ada juga orang yang kurang begitu bagus irama dalam pembacaan Al-Qur'annya akan tatapi ia mampu memahami tajwidnya.

a. Bulan Pertama

Sebelum pembelajaran dimulai pada pertemuan pertama, peserta didik dibekali dengan materi pengarahan tentang cara penggunaan metode Iqra' dilanjutkan dengan tes kemampuan membaca Al-Qur'an untuk menetapkan kelompok. Hasil yang diperoleh bervariasi dari iqra' 1 sampai iqra' 5.Dibawah ini kemampuan awal peserta didik dalam membaca Al-Qur'an hasil pretest yang dilakukan oleh Tim pada tanggal 17 September 2020 sebagai berikut:

\begin{tabular}{|c|l|l|l|}
\hline No. & Nama & Kelas & \multicolumn{1}{|c|}{ Iqra' } \\
\hline 1 & Dibah & TK & 1 halaman 5-7 \\
\hline 2 & Alya & TK & 1 halaman 5-7 \\
\hline 3 & Abizar & TK & 1 halaman 5-8 \\
\hline 4 & Rido & TK & 1 halaman 5-8 \\
\hline 5 & Okta & 1 SD & 1 halaman 5-8 \\
\hline 6 & Yusuf & 1 SD & $\begin{array}{l}1 \text { halaman 5- } \\
10\end{array}$ \\
\hline 7 & Nuratisah & 1 SD & 1 halaman 5-7 \\
\hline 8 & Ayunda & 1 SD & 1 halaman 5-9 \\
\hline 9 & $\begin{array}{l}\text { Atika } \\
\text { Deviani }\end{array}$ & 1 SD & 2 halaman 3-7 \\
\hline 10 & Humairo & 1 SD & 4 halaman 3-9 \\
\hline
\end{tabular}


Samsidar,dkk. Bimbingan Belajar Membaca Al-Qura’an...

\begin{tabular}{|c|l|l|l|}
\hline 11 & $\begin{array}{l}\text { Aji } \\
\text { Aliando } \\
\text { Alfarizi }\end{array}$ & 2 MIN & $\begin{array}{l}4 \text { halaman 3 - } \\
7\end{array}$ \\
\hline 12 & $\begin{array}{l}\text { Aji } \\
\text { Afriandi }\end{array}$ & 2 MIN & $\begin{array}{l}4 \text { halaman 3 - } \\
7\end{array}$ \\
\hline 13 & Rizki & 2 SD & $\begin{array}{l}1 \text { halaman 5 - } \\
10\end{array}$ \\
\hline 14 & Ahir & 3 MIN & $\begin{array}{l}1 \text { halaman 5 - } \\
10\end{array}$ \\
\hline 15 & $\begin{array}{l}\text { Rizki } \\
\text { Rahadi }\end{array}$ & 4 SD & $\begin{array}{l}5 \text { halaman 3 - } \\
7\end{array}$ \\
\hline 16 & Munah & 4 SD & $\begin{array}{l}4 \text { halaman 3 - } \\
8\end{array}$ \\
\hline 17 & Mulkan & 4 SD & $\begin{array}{l}3 \text { halaman 3 - } \\
7\end{array}$ \\
\hline 18 & Romi & 5 SD & $\begin{array}{l}3 \text { halaman 3 - } \\
8\end{array}$ \\
\hline 19 & Awal & 5 SD & $\begin{array}{l}3 \text { halaman 3 - } \\
7\end{array}$ \\
\hline
\end{tabular}

Perkembangan Pembelajaran

hasil tes pada tanggal 30 September 2020 sebagai berikut:

\begin{tabular}{|c|c|c|c|}
\hline No. & Nama & Kelas & Iqra' \\
\hline 1 & Dibah & TK & 1 halaman 16 \\
\hline 2 & Alya & TK & 2 halaman 12 \\
\hline 3 & Ayunda & $1 \mathrm{SD}$ & 1 halaman 12 \\
\hline 4 & Vania & $2 \mathrm{SD}$ & 1 halaman 9 \\
\hline 5 & Okta & $1 \mathrm{SD}$ & 1 halaman 5 \\
\hline 6 & Yusuf & $1 \mathrm{SD}$ & 1 halaman 5 \\
\hline 7 & Nuratisah & $1 \mathrm{SD}$ & 1 halaman 5 \\
\hline 8 & $\begin{array}{l}\text { Aji } \\
\text { Afriandi }\end{array}$ & $\begin{array}{l}2 \\
\text { MIN }\end{array}$ & 4 halaman 17 \\
\hline 9 & Rizki & $2 \mathrm{SD}$ & 1 halaman 8 \\
\hline 10 & Humairo & $1 \mathrm{SD}$ & 4 halaman 25 \\
\hline 11 & Munah & $4 \mathrm{SD}$ & 4 halaman 18 \\
\hline 12 & Rosita & TK & 1 halaman 5 \\
\hline 13 & Alul & $\begin{array}{l}3 \\
\text { MIN }\end{array}$ & 2 halaman 9 \\
\hline 14 & Ahir & $\begin{array}{l}3 \\
\text { MIN }\end{array}$ & 1 halaman 10 \\
\hline 15 & Syahrul & $\begin{array}{l}3 \\
\text { MIN }\end{array}$ & Al-Qur'an \\
\hline 16 & Rafa & $3 \mathrm{SD}$ & 2 halaman 5 \\
\hline 17 & Anggi & $6 \mathrm{SD}$ & Al-Qur'an \\
\hline
\end{tabular}

\section{b. Bulan ke Dua}

Indikator keberhasilan dalam membaca Al-Qur'an tidak terlalu maksimal sampai mereka benar-benar bisa baca Al-Qur'an dengan bacaan tajwid yang baik dan benar, karena kegiatannya hanya dilakukan 2 kali seminggu setiap hari Rabu dan Kamis dengan waktu yang terbatas hanya 3 jam sehari yaitu dari jam $14.00 \mathrm{~s} / \mathrm{d}$ 17.00. Sedangkan peserta didiknya sering tidak tetap dan berganti-ganti sehingga pembelajaran tidak tuntas.

Pembelajaran terakhir hasil tes dibulan kedua pada tanggal 14 Oktober 2020 sebagai berikut:

\begin{tabular}{|c|c|c|c|}
\hline No. & Nama & Kelas & Iqra' \\
\hline 1 & Dibah & TK & 1 halaman 24 \\
\hline 2 & Alya & TK & 2 halaman 21 \\
\hline 3 & Rafa & $3 \mathrm{SD}$ & 2 halaman 15 \\
\hline 4 & Syahrul & $\begin{array}{l}3 \\
\text { MIN }\end{array}$ & Al-Qur'an \\
\hline 5 & Bilal & $1 \mathrm{SD}$ & 3 halaman 8 \\
\hline 6 & Alul & $\begin{array}{l}3 \\
\text { MIN }\end{array}$ & 2 halaman 26 \\
\hline 7 & Mulkan & $4 \mathrm{SD}$ & 4 halaman 11 \\
\hline 8 & $\begin{array}{l}\text { Rizki } \\
\text { Rahadi }\end{array}$ & $4 \mathrm{SD}$ & 5 halaman 13 \\
\hline 9 & Abizar & TK & 1 halaman 35 \\
\hline 10 & Romi & $5 \mathrm{SD}$ & 3 halaman 20 \\
\hline 11 & Okta & $1 \mathrm{SD}$ & 1 halaman 35 \\
\hline 12 & Rizki & $2 \mathrm{SD}$ & 1 halaman 35 \\
\hline 13 & Awal & $5 \mathrm{SD}$ & 2 halaman 31 \\
\hline 14 & Vania & $2 \mathrm{SD}$ & 1 halaman 35 \\
\hline 15 & Munah & $4 \mathrm{SD}$ & 4 halaman 13 \\
\hline 16 & Naila & $1 \mathrm{SD}$ & 1 halaman 32 \\
\hline 17 & Nadifa & $2 \mathrm{SD}$ & Al-Qur'an \\
\hline 18 & Ara & TK & 1 halaman 13 \\
\hline 19 & Aida & $3 \mathrm{SD}$ & 2 halaman 24 \\
\hline
\end{tabular}




\begin{tabular}{|c|l|l|l|}
\hline 20 & Kirana & 3 SD & 2 halaman 23 \\
\hline 21 & Naiya & TK & 1 halaman 13 \\
\hline 22 & Ransi & 2 SD & 1 halaman 28 \\
\hline 23 & Atisah & 1 SD & 1 halaman 19 \\
\hline
\end{tabular}

Masyarakat sangat antusias dengan program ini, karna selama pandemi covid-19 anak-anak tidak belajar mengaji karena tempat pengajian mereka tidak membuka kegiatan.Data ini diperoleh hasil wawancara dengan salah seorang peserta didik.Tim mengakhiri kegiatan pembelajaran pada tanggal 14 Oktober 2020, program dilanjutkan oleh Rifki salah seorang mahasiswa semester V Fakultas Agama Islam Universitas Muhammadiyah Tapanuli Selatan yang didanai oleh donatur dari dosen Fakultas Agama Islam Universitas Muhammadiyah Tapanuli Selatan.

\section{SIMPULAN}

a. Kegiatan PKM ini dilakukan hanya 2 kali seminggu setiap hari Rabu dan Kamis dengan waktu yang terbatas hanya 3 jam sehari yaitu dari jam $14.00 \mathrm{~s} / \mathrm{d} 17.00$.

b. Keberhasilan dalam membaca AlQur'an tidak terlalu maksimal sampai mereka benar-benar bisa baca Al-Qur'an karena. peserta didiknya sering tidak tetap dan berganti-ganti sehingga pembelajaran tidak tuntas.

c. Program dilanjutkan oleh Rifki salah seorang mahasiswa semester V Fakultas Agama Islam Universitas Muhammadiyah Tapanuli Selatan yang didanai oleh donatur dari dosen Fakultas Agama Islam Universitas Muhammadiyah Tapanuli Selatan.

\section{DAFTAR PUSTAKA}

Baduwailan, Ahmad. 2017. Menjadi Hafizh Tips \& Motivasi Menghafal Al-Qur'an. Solo: Aqwam.

Humam, As’ad. 2017. Buku Iqro' Cara Cepat Membaca Al-Qur'an. Yogyakarta: Balai Litbang LPTO Nasional.

Lathif, Abdul.2018. Belajar Tajwid untuk Pemula. Yogyakarta: Barokah Books.

Zen, Endi Suhendi. 2013. Panduan Baca Tulis Al-Qur'an. Jakarta Timur: CV. Indradjaya. 